\title{
A PESQUISA SOBRE PUBLICIDADE E PROPAGANDA EM SAÚDE PÚBLICA NA SCIELO
}

\author{
The search About Public Health Advertising at SciELO
}

La Investigación en Publicidad en Salud Pública en SciELO

Dhione Oliveira Santana

Programa de Pós-graduação em Ciências da Comunicação

Universidade Federal de Sergipe

e-mail: odhione@gmail.com

Raquel Marques Carriço Ferreira

Professora do Programa de Pós-graduação em Ciências da Comunicação

Universidade Federal de Sergipe

e-mail: raquelcarriço@gmail.com

\section{Resumo}

As mensagens publicitárias são dotadas de argumentos persuasivos capazes de influenciar crenças, opiniões, atitudes e comportamentos, podendo impactar profundamente a saúde pública de uma determinada geografia. Nesse sentindo, nosso estudo objetivou mapear as pesquisas sobre publicidade e propaganda na saúde pública na Coleção Saúde Pública na base de dados da SciELO. Nossa análise contemplou os estudos publicados entre os anos 1983 a 2018, sendo os termos utilizados na busca publicidade e propaganda em português, inglês e espanhol. Os resultados demonstraram os temas abordados estavam relacionados com a regulamentação publicitária, e mercado de consumo, sobretudo, de produtos e substâncias que ocasionam mal à saúde ou que promoveriam a saúde, a maioria dos estudos foram publicados em periódicos brasileiros e realizados por pesquisadores brasileiros vinculados às Ciências da Saúde

Palavras-chave: Comunicação Publicitária. Saúde Pública. Produção Científica.

\begin{abstract}
Advertising messages are endowed with persuasive arguments capable of influencing beliefs, opinions, attitudes and behaviors, which can profoundly impact the public health of a given geography. In this sense, our study aimed to map the research on advertising and public health in the Public Health Collection in the SciELO database. Our analysis included studies published between the years 1983 to 2018, with the terms used in the search for advertising in Portuguese, English and Spanish. The results showed thar the topics covered were related to advertising regulation, and consumer market, above all, of products and substances that cause harm to health or that would promote health, most of the studies were published in Brazilian journals and carried out by Brazilian researchers to Health Sciences.
\end{abstract}

Key-words: Advertising Communication. Public health. Producción Científica. 


\section{Resumen}

Los mensajes publicitarios están dotados de argumentos persuasivos capaces de influir en creencias, opiniones, actitudes y comportamientos, que pueden tener un impacto profundo en la salud pública de una determinada geografía. En este sentido, nuestro estudio tuvo como objetivo mapear la investigación sobre publicidad y salud pública en la Colección Salud Pública en la base de datos SciELO. Nuestro análisis incluyó estudios publicados entre los años 1983 a 2018, con los términos utilizados en la búsqueda de publicidad y publicidad en portugués, inglés y español. Los resultados mostraron que los temas abordados estaban relacionados con la regulación publicitaria, y el mercado de consumo, sobre todo, de productos y sustancias que causan daños a la salud o que promoverían la salud, la mayoría de los estudios fueron publicados en revistas brasileñas y realizados por investigadores brasileños vinculados a las Ciencias de la Salud.

Palabras clave: Comunicación Publicitaria. Salud Pública. Palabra clave.

\section{INTRODUÇÃO}

A publicidade e a propaganda, nesse estudo entendidas como palavras sinônimas, são importantes ferramentas originalmente do marketing, com objetivos mercadológicos que podem ser adaptadas a qualquer objetivo social. São de fato, técnicas cujo objetivo é o de persuadir um determinado público-alvo a se motivar a experimentar e/ou aceitar uma determinada ideia, produto (no caso da saúde, medicamento, tratamento etc.) ou adotar novas atitudes e comportamentos em prol às mensagens difundidas pelo anunciante, (PINTO, 1997, CARVALHO, 2004 e 2014, CARRASCOZA, 2004, VESTERGAARD e SCHRODER, 2004), como adotar estilos de vida saudáveis, fazer exercícios físicos, ou uma alimentação saudável, adotar comportamentos baseados em medidas sanitárias, como lavar as mãos, usar determinados equipamentos de proteção ou ainda mesmo eliminar foco de vetores propagadores de doenças.

No mundo capitalista, a publicidade começou a exercer um importante papel, a de fomentar demandas por produtos fabricados a partir da Revolução Industrial, produtos agora excedentes à capacidade natural de absorção antes não configurada. Segundo Eloá Muniz (2004, p. 01), a publicidade existe desde a Idade Clássica, porém, sua função era a de primordialmente, informar. Foi com a Revolução Industrial que a linguagem publicitária se aprimora e passa a ser argumentativa, ou seja, "persuasiva", um grande trunfo do mercado do consumo.

A persuasão, operada por meio da publicidade, nada mais é do que uma estratégia argumentativa de comunicação que consiste em utilizar recursos racionais, emocionais e 
simbólicos para influenciar, motivar alguém a aceitar uma ideia, uma atitude, ou um novo comportamento. Enquanto ferramenta associada ao consumo capitalista e a busca incessante das empresas pelo lucro, a publicidade tornou-se, na visão de muitos pensadores e/ou pesquisadores como Bauman (2008) e Coelho (2003), Federigui (1999) co-vilã dos males ocasionados pelo consumo desenfreado de produtos que ocasionam diversos males ou de comportamentos nocivos à saúde; desde o desperdício de recursos naturais e a poluição do meio ambiente até práticas inadequadas que prejudicam a saúde do indivíduo em sociedade, como o consumo desequilibrado de calorias, sedentarismo, distúrbios psíquicos (compulsões) e relacionais, entre outros. Todavia, a mesma publicidade que estimula comportamentos não saudáveis também é a mesma que pode ser usada para conscientizar e promover boas práticas de saúde e autocuidado.

É fundamental reconhecer a publicidade como importante agente influenciador da saúde pública, seja para o bem ou para o mal, o que tem despertado o interesse de estudiosos dentro inúmeras áreas do saber, da área da Linguística à Psicologia social, da Administração de Marketing à Comunicação, do Direito à Antropologia. Nesse sentido, buscamos mapear os estudos sobre publicidade e propaganda na saúde pública, por meio de um estudo bibliométrico junto à Coleção Saúde Pública da base de dados da SciELO (Scientific Electronic Library Online), desde o ano da primeira obra relacionada, 1983, até o ano de 2018.

\section{A PUBLICIDADE COMO ESTRATÉGIA DO CAMPO DA COMUNICAÇÃO E SAÚDE E SUAS LIMITAÇÕES}

Todos os anos bilhões de dólares são gastos em campanhas publicitárias direcionadas para promoção da saúde e consequentemente do bem-estar (YOM-TOV, et al, 2018). A comunicação publicitária é uma importante ferramenta de promoção da saúde e prevenção de doenças, podendo fomentar mudanças de comportamentos dos indivíduos e comunidades que trazem resultados positivos para a saúde da população geral (SCHIAVO, 2013). Mais recentemente, na pandemia da Covid-19, por exemplo, diversas foram as campanhas publicitárias criadas com o objetivo de fazer com que a população adotasse medidas que mitiguem o contágio do vírus SARS-CoV-2, com mensagens sobre o uso de máscara e de álcool em gel, lavagem das mãos, isolamento social e a aderência às campanhas de vacinação. 
Para que a publicidade seja uma ferramenta efetiva, de acordo com McGuire (1984) apud Schiavo (2013), o indivíduo precisa se sentir impelido a se expor à mensagem, precisa dar sua atenção à mensagem, precisa se interessar, compreender, aceitar os argumentos apresentados e passe a acreditar que a mudança ou reforço do seu comportamento é um esforço que vale a recompensa adquirida com essa nova conduta. $\mathrm{O}$ argumento para esse novo comportamento precisa se encaixar em sua vida, precisa fazer com que ele pense na mensagem em contextos ou situações relevantes, precisa fazer com que ele tome decisões, comporte-se de acordo com essa decisão, receba reforço positivo por esse comportamento.

A publicidade, embora seja uma ferramenta importante para a promoção da saúde, de outro lado, também não faz milagres e tem suas limitações. Como parte do composto de marketing, depende de outras ações de comunicação em conjunto para atingir seus objetivos propostos. Precisa da construção de um ambiente favorável, ela não pode compensar soluções médicas inadequadas, e prescinde de outro conjunto de infraestrutura mínima para realização de determinada ação de saúde (CORCORAN, 2013). A par das suas capacidades e limitações, o que de facto sabemos a respeito do conhecimento gerado pelo estudo da publicidade e Saúde Pública? O que podemos inferir desse campo de pesquisa? Essas são as perguntas que guiam nosso empreendimento nesse estudo.

\section{A SCIELO E A COLEÇÃO SAÚDE PÚBLICA}

A SciELO é uma base de dados criada pela a FAPESP (Fundação de Amparo à Pesquisa de São Paulo), em parceria com a Bireme (Centro Latino-Americano e do Caribe de Informação em Ciências da Saúde), com apoio financeiro do CNPq (Conselho Nacional de Desenvolvimento Científico e Tecnológico) que possui artigos indexados em Coleções por países (Brasil, África do Sul, Argentina, Bolívia, Colômbia, Costa Rica, Cuba, Chile, Espanha, México, Peru, Portugal, Uruguai, Venezuela e Paraguai) e coleções especiais que incluem temas específicos ("Saúde Pública", "Social Sciences", "West Indian Medical Journal" e "Brasil Proceeding").

A Coleção Saúde Pública faz parte de um conjunto de periódicos científicos de acesso gratuito que reúne trabalhos sobre Saúde e suas especificidades, tais como planejamento e gestão, ciências sociais e saúde pública, promoção e intervenções de saúde e epidemiologia de várias partes do mundo. Neste sentido a publicidade e propaganda se insere no campo da 
saúde por ser uma ferramenta capaz de interferir direta ou indiretamente em diversos processos que determinam a saúde e doença das populações.

Em números, a Coleção Saúde Pública reunia de forma indexada em março de 2019, 18 periódicos do Brasil, 02 da Espanha, e 01 da Argentina, Estados Unidos, Colômbia Cuba, México e Peru, além da publicação da Organização Pan-Americana da Saúde (uma das mais antigas organizações de saúde que visa melhorar as condições de saúde na região das Américas). Foram publicadas, até março de 2019, 2278 edições, 42266 artigos com 568747 citações (SCIELO - COLEÇÃO SAÚDE PÚBLICA, 2019). Em síntese, trata-se de um dos maiores espaços para divulgação de trabalhos científicos relacionados à saúde pública em um contexto predominantemente ibero-americano, muito embora, não só.

\section{ABORDAGEM METODOLÓGICA}

O trabalho aqui desenvolvido é abordado pela lógica quantitativa, descritiva, exploratória, de caráter documental, baseada em técnicas bibliométricas. A pesquisa quantitativa considera que tudo pode ser quantificável, o que significa traduzir em números, opiniões e informações para classificá-las e analisá-las (SILVA e MENEZES 2001, p. 21). Para Mattar (1997, p.80) a pesquisa exploratória "visa prover ao pesquisador, um maior conhecimento sobre o tema ou problema de pesquisa em perspectiva”. A pesquisa descritiva, segundo Gil (2008), visa descrever “determinados fenômenos”. A análise documental compreende a identificação e apreciação de documentos para determinados fins, como o da descrição da produção científica de uma determinada área do saber (SILVA e MENEZES, 2011, p. 271).

Por fim, a bibliometria é um método da pesquisa definida por Lakatos e Marconi (2001, p. 43-44) como o "levantamento de toda bibliografia já publicada, visando [...] colocar o pesquisador em contato direto com tudo aquilo que foi escrito sobre determinado assunto". Assim, o trabalho aqui desenvolvido tem caráter quantitativo, pois, tem o objetivo de analisar a totalidade da produção acadêmica publicada na base SciELO nos nossos termos definidos, é descritiva, pois, descreve as características das pesquisas produzidas, é exploratória, pois, nos possibilita como resultado, uma sondagem do objeto estudado, é documental, pois, é baseada na análise dos documentos, artigos publicados, seus conteúdos, e é sobretudo, bibliométrica, pois, resulta em um levantamento da bibliografia produzida sobre o tema que exploramos. 
Os dados analisados foram retirados dos artigos científicos que dão conta dos termos "Publicidade" e "Propaganda" em português, inglês e espanhol (Publicidade", "Propaganda", "Advertising", "Publicidad" e "Advertisement"), entre janeiro e abril de 2019. Foram analisados todos os estudos presentes na plataforma, de 1983 até o ano de 2018.

As categorias do objeto de análise foram: a) Ano de Publicação, que diz respeito à evolução das publicações sobre os termos empregados; b) Revista, diz respeito aos periódicos indexados na Coleção Saúde Pública em que o artigo foi publicado; c)Nacionalidade, diz respeito ao país de origem dos pesquisadores das pesquisas observadas; d) Área de conhecimento, diz respeito à área profissional ao qual os pesquisadores graduaram ou pós graduaram; e) Produto Temático, apresenta o objeto de interesse estudado que é associado à publicidade e saúde pública; f) Enfoque Temático, diz respeito sobre a perspectiva ou abordagem dos estudos analisados.

\section{APRESENTAÇÃO E ANÁLISE DOS RESULTADOS}

Em nosso levantamento inicial, encontramos 42 artigos associados à palavra publicidade, 66 à propaganda, 104 à publicidad, 132 à advertising e 23 à advertisement. Depois da análise inicial dos conteúdos dos textos publicados e a exclusão dos materiais repetidos ou que não faziam parte do escopo do nosso estudo, foram selecionados 110 artigos para análise.

De acordo com os resultados, verificamos um lento, mas consistente crescimento no número de publicações, em uma imagem em que notamos uma espécie de ondas, em que vemos perpetuar um aumento, mas com momentos de regressão no número de publicações. A partir de 2006 verificamos a existência de um momento particular em que 5 artigos científicos foram publicados em um único ano. A partir daí, a média de publicações se eleva, tendo os anos de 2012, 2013 e 2017 como os maiores em número de artigos publicados, com 11 artigos nos dois primeiros anos citados, e 14 no terceiro. Também notamos importante o primeiro artigo recuperado na plataforma, datado de 1983, ano anterior a criação da plataforma SciELO. 
Figura 1 - Número de Artigos por Ano de Publicação

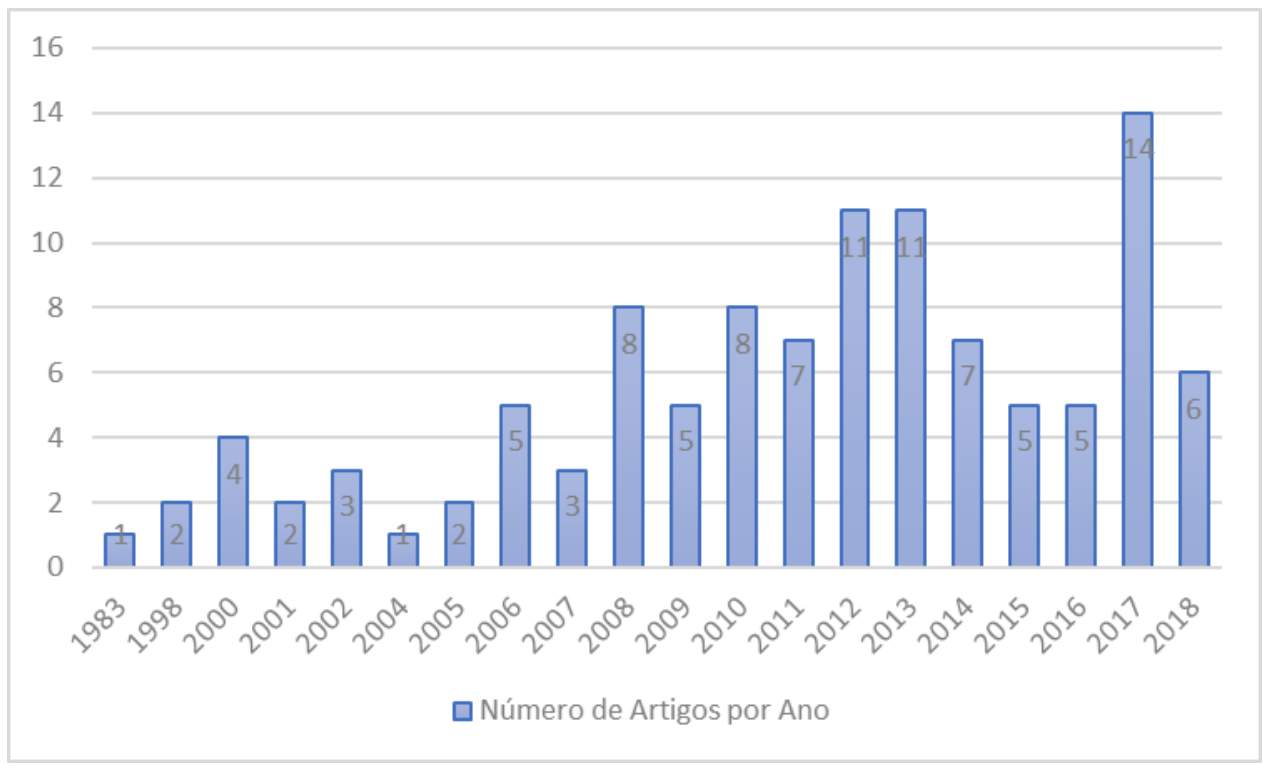

Fonte: Elaborado pelos autores.

Observando os dados acima apresentados, podemos inferir sobre a pequena oscilação no número de artigos publicados que pode ser associada ao fato de a publicidade e propaganda não ser um objeto especificamente correlato à área da saúde, embora, um objeto que a afete, direta ou indiretamente. O número pequeno total de artigos associado ao tema da publicidade e saúde, 110 artigos ao longo de 35 anos da Coleção Saúde Pública, nos indica um baixo interesse dos pesquisadores sobre essa relação, sobretudo no Brasil, país que, como veremos, é o maior produtor de artigos da área aqui privilegiada.

Quanto ao país das publicações, verificamos que 45,1\% eram de origem brasileira, $17,5 \%$ de origem espanhola, $9 \%$ mexicana, $7,2 \%$ norte-americana, $4,2 \%$ colombiana, $4,0 \%$ argentina, $3,7 \%$ chilena, $2,1 \%$ australiana, $1,7 \%$ peruana, com $1,06 \%$ do total foram encontradas publicações de origem uruguaia, canadense, moçambicana, 0,53\% de origem portuguesa e romena, além de $0,26 \%$ de origem turca, belga e sul-africana. 
Figura 3 - Nacionalidade dos Autores

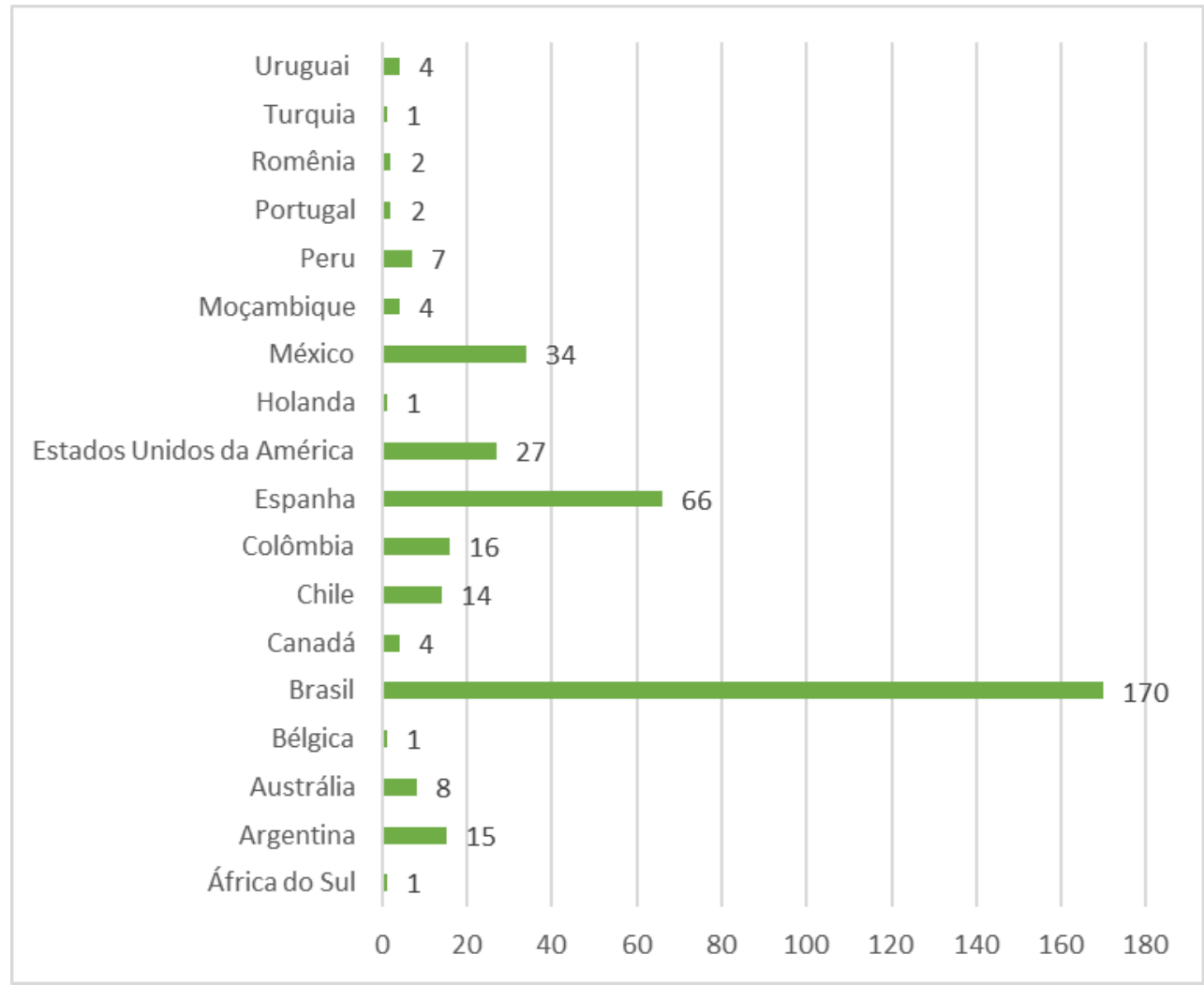

Fonte: Elaborado pelos autores.

Ao se observar os dados apresentados acima, percebemos também que o número de autores é 3 vezes maior do que o número de trabalhos, fato esse associado à média de 3,4 autores por trabalho publicado, condição comum nas publicações científicas da área da saúde, mas, superdimensionada quando considerada a tradição na área das ciências sociais aplicadas. Por fim notamos que, dos artigos estrangeiros publicados nos periódicos relacionados, a maior parte é de origem ibero-americana, o que denota não só um pequeno alcance em termos de internacionalização desses periódicos como também, um reduto mais homogêneo de debates de problemáticas mais concentradas nesse ambiente geográfico.

Em relação aos periódicos em que os estudos foram publicados, verificamos que 17 dos 18 periódicos indexados na Coleção Saúde Pública da SciELO nos retornaram material de estudo. Desses, 59 artigos ou $(53,6 \%)$ das publicações foram encontradas em revistas brasileiras e 46,4\% em periódicos de origem estrangeira. As revistas com o maior número de publicações foram as Revistas Ciência \& Saúde Coletiva e Salud Pública de México, com 16 publicações ou 14,6\% cada uma, seguidas pelas Revista Saúde Pública (14 artigos ou 12,7\%), Cadernos de Saúde Pública (11 artigos ou 10\%) e Gaceta Sanitaria (10 artigos ou 9\%). O 
periódico que não encontramos artigo algum sobre publicidade em saúde foi a revista cubana MEDICC Review.

Figura 2 - Número de Artigos por Revista

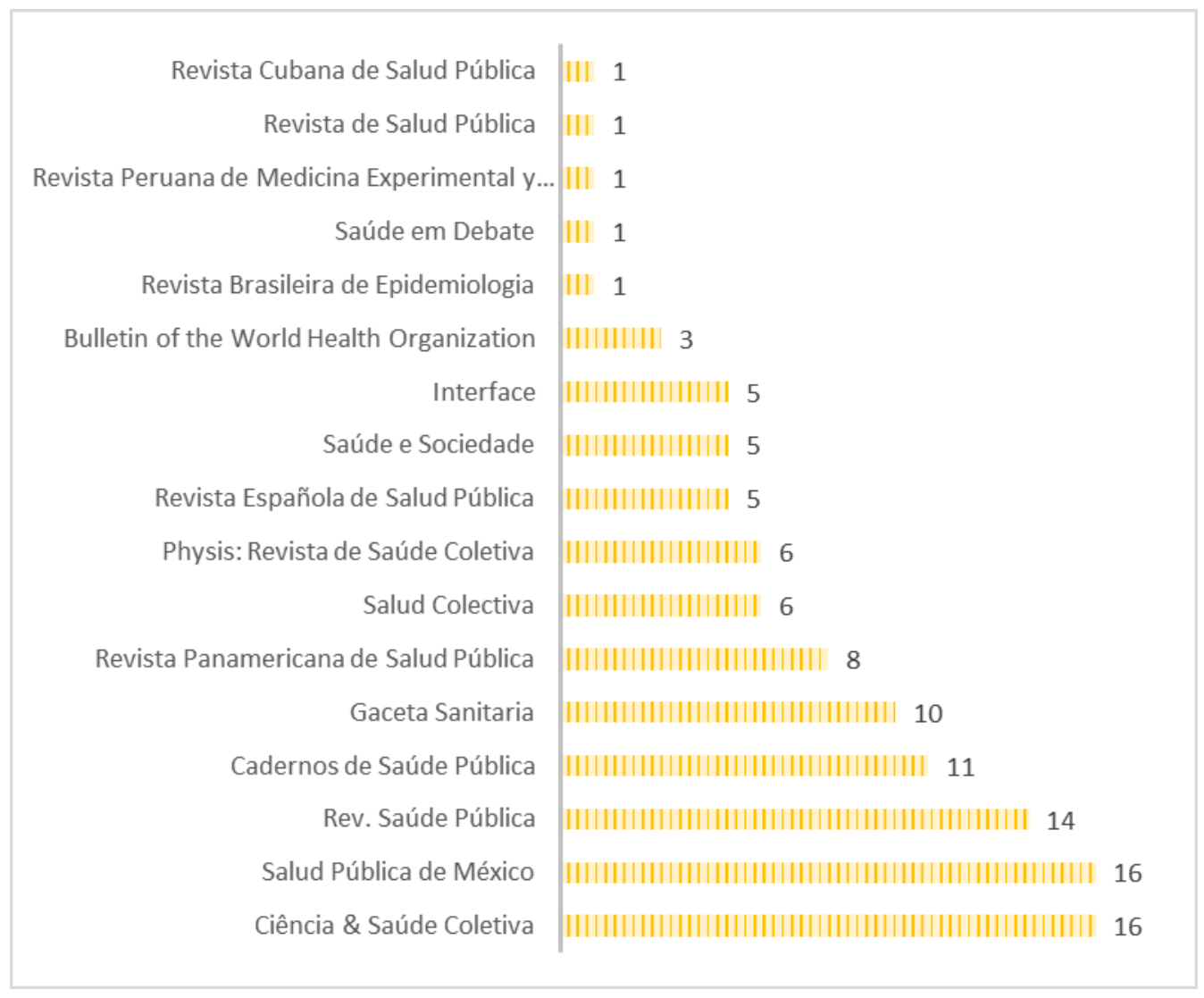

Fonte: Elaborado pelos autores.

A predominância de artigos científicos em revistas brasileiras (Ciência \& Saúde Coletiva (16), Revista Saúde Pública (14), Cadernos de Saúde Pública (11), Physis: Revista de Saúde Coletiva (6), Saúde e Sociedade (5), Interface (5), Revista Brasileira de Epidemiologia (1), Saúde em Debate (1), reflete a importância acadêmica dos periódicos nacionais na área da saúde pública no contexto ibero-americano no que diz respeito ao estudo da publicidade, isso porque, mesmo com predominância de produções brasileiras, 54,9\% das publicações são de autores estrangeiros, ou seja, autores estrangeiros têm procurado as revistas brasileiras para publicação (observar gráfico anterior).

Também não podemos deixar de observar que a SciELO é um projeto idealizado por instituições brasileiras, logo, é de se esperar que a maioria dos estudos, $(53,6 \%)$ das publicações, tiveram sua origem em revistas brasileiras. 
No que diz respeito a ausência de publicações no periódico cubano MEDICC Review, sugerimos a ideia de que a publicidade é comumente uma prática associada ao sistema capitalista, o que não deve despertar interesse dos editores e estudiosos dessa nação.

No que diz respeito à área de conhecimento dos autores, verificamos que, baseado em dados sobre Áreas do Conhecimento da Capes e do $\mathrm{CNPq}^{1}, 47,7 \%$ dos trabalhos estavam ligados à área das Ciências da Saúde, 14,1\% a área das Ciências Sociais Aplicadas, 2,6\% na área das Exatas, 1,3\% na área das Ciências Biológicas, 0,53\% Letras, Linguística e Artes, 0,53\% na área das Engenharias e 32,6\% não foi possível identificar ou não foi informada.

Figura 4 - Formação dos Autores por Profissão

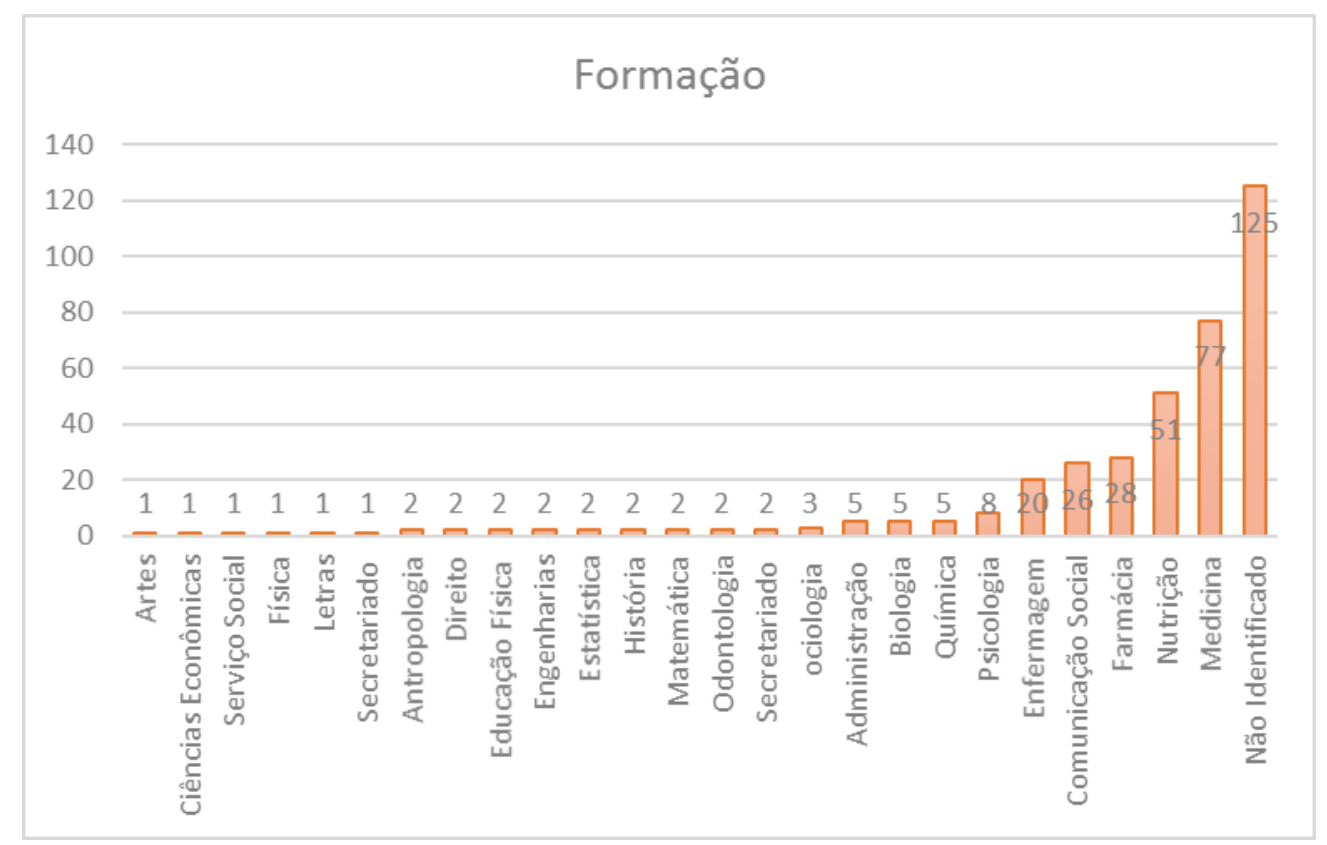

Fonte: Elaborado pelos autores

Nos valendo de dados apresentados adiante, vemos que as formações prevalecentes dos autores dos artigos avaliados permanecem entre as áreas da saúde como Medicina, Nutrição, Farmácia e Enfermagem e assim, quem tem se debruçado sobre a possível correlação entre publicidade e saúde, são autores com pouco acúmulo de conhecimento na área das ciências sociais aplicadas, um background importante para a desconstrução ou avaliação de tais relações, o que faria do acúmulo de publicações, mesmo pequeno.

Uma vez que autores das áreas das ciências sociais aplicadas como a psicologia social, psicologia, sociologia, antropologia, comunicação social, entre outros, se interessassem pelas 
relações da publicidade e saúde, muito provavelmente, teríamos um acúmulo muito maior e mais rico de estudos, sobretudo no país. Essa necessidade de especialistas das ciências sociais pesquisando saúde se mostra não apenas fundamental pelo pequeno número de produções científicas encontradas ao longo dos últimos 35 anos, mas também, pela variedade de problemas encontrados hodiernamente dentro do campo da comunicação e saúde que demandam estudos científicos que prescinde do entendimento do uso das estratégias persuasivas como as fake News em saúde; as contra campanhas de vacinação; a publicitação de alimentos ricos em gordura e açucares, de estilos de vida sedentários e ou de alto risco à saúde; da publicitação de ideias em prol à liberação do porte de armas, da conscientização de condutas responsáveis no trânsito, de estratégias de autogerenciamento da saúde da população, da publicidade de medicamentos e a automedicação, de políticas públicas em comunicação e saúde, etc..

Ao analisar o conteúdo dos artigos publicados na Coleção Saúde Pública da SciELO, no que diz respeito ao produto temático, categorizamos 10 objetos de pesquisa distintos. Os estudos sobre publicidade de alimentos concentravam a maioria das publicações encontradas, 33 (30\%) trabalhos, os estudos sobre medicamentos e tabaco vieram em seguida com 29 (26,4\%) trabalhos, Bebidas Alcoólicas 9 (8,2\%) dos trabalhos, serviços da saúde em geral 4 $(3,6 \%)$, inseticida $2(1,8 \%)$, vacina, preservativo, hospital e Aedes Aegypti apenas $1(0,9 \%)$ estudo cada.

Figura 5 - Número de Artigos de Acordo com Produto e/ou Serviço Temático

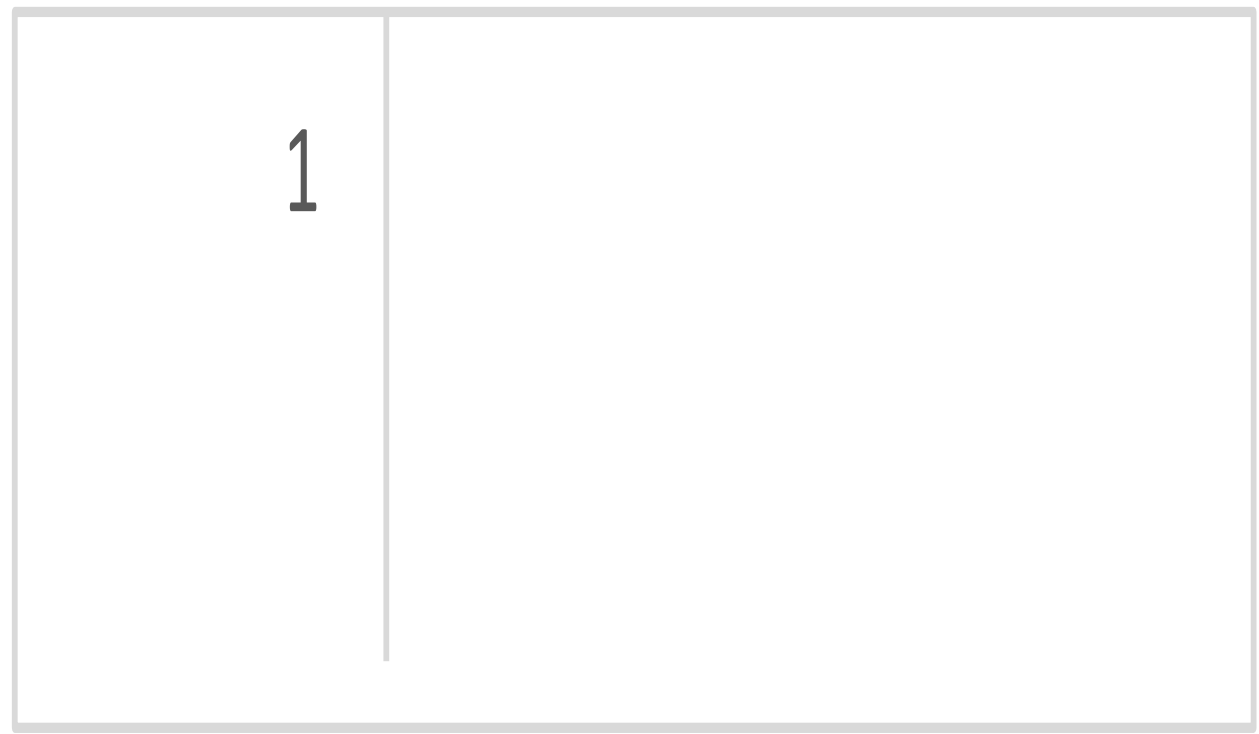


Fonte: Elaborado pelos autores.

Os estudos sobre alimentos envolveram tanto trabalhos sobre comidas sólidas como líquidas, como refrigerantes e bebidas açucaradas. Nessa categoria temática, estiveram presentes as análises da publicidade e seus impactos negativos na saúde pública, bem como a publicidade de comidas saudáveis e o patrocínio de atividades físicas pela indústria de alimentos, como uma estratégia mercadológica de relações públicas do setor.

Em relação ao produto temático Medicamentos, foram encontrados tanto trabalhos que tratavam da análise de estratégias publicitárias da indústria farmacêutica direcionadas aos profissionais da área da saúde, como também ao público em geral.

$\mathrm{Na}$ análise do produto temático tabaco, os estudos trataram como o controle e restrições da propaganda afetaram o seu consumo, analisaram estratégias publicitárias de promoção das indústrias tabageiras, e a analisaram campanhas publicitárias contra o consumo.

Os estudos sobre bebidas alcoólicas analisaram como a publicidade interfere direta e indiretamente no consumo desse produto, também foram feitas análises de regulamentações no que diz respeito a publicidade desse tipo de produto.

Os estudos sobre serviços de saúde em geral por sua vez foram estudos que analisaram a publicidade de algum serviço de saúde sem especificar o serviço, como por exemplo o estudo "La representación de servicios de salud en la televisión mexicana: potenciales consecuencias en las subjetividades en salud" (ROJAS RAJS, 2016).

Os dois estudos sobre inseticidas buscaram analisar campanhas publicitárias de inseticidas relacionados à saúde, sendo que um dos estudos tratou dos riscos dos inseticidas ao meio ambiente e a saúde dos consumidores. Já o outro estudo avaliou as estratégias publicitárias para persuadir o público-alvo, como produtos que representavam a solução para resolver problemas com os insetos na década de 1960.

Por seguinte, o estudo em que o produto temático era a comunicação organizacional de um hospital, este foi desenvolvido a partir de uma perspectiva dos profissionais de saúde na construção de sentidos de anúncios impressos hospitalares.

No caso do produto temático vacina foi feita uma análise da retirada de uma campanha publicitária feita para promover a vacina contra o vírus Papiloma Humano (HPV) na Espanha, que segundo os pesquisadores violou a legislação espanhola pois se tratava de uma campanha patrocinada por um laboratório particular, o que é proibido pelas leis espanhola. 
Sobre o produto temático preservativo, o único estudo encontrado analisou o discurso publicitário sobre a camisinha nas campanhas para a prevenção de doenças sexualmente transmissíveis (DSTs) através de uma perspectiva funcional e lúdica, sugerindo que para uma maior eficácia, as campanhas de combate poderiam associar o uso da camisinha ao prazer e a segurança. Foram analisadas três campanhas publicitárias de anunciantes distintos: a primeira foi a campanha "Bráulio" do Ministério da Saúde veiculada em 1995, a segunda campanha "Depoimentos" - do GAPA/BA (Grupo de Apoio à Prevenção à AIDS da Bahia) veiculada em 1997 e a terceira foi a campanha de prevenção da Aids produzida pela MTV em 1997.

Por fim, sobre o produto temático Aedes Aegypti, o estudo analisou os sentidos publicitários de algumas campanhas sobre a prevenção das doenças tropicais (Dengue, Zika e Chikungunya) provocadas pelo Aedes Aegypti. Os cinco anúncios analisados foram escolhidos de forma aleatória pelos pesquisadores e dizem respeito a campanhas com anunciantes e período de veiculação distintos. O primeiro anúncio foi veiculado pela coordenação de vigilância em saúde - COVISA - da Secretaria de Saúde da Prefeitura da cidade de São Paulo de 2013, o segundo anúncio diz respeito ao combate à Dengue e foi veiculado pela Secretaria de Saúde - Governo da Bahia, 2013, o terceiro visava combater a Dengue Chikungunya Zika Vírus e foi veiculada pela Prefeitura de Cocalzinho de Goiás, 2016, a quarta tem origem desconhecida, todavia também visava combater a Dengue Chikungunya Zika Vírus e o quinto foi veiculado pela Universidade Federal do Rio Grande do Norte, 2016 e visava combater a Dengue Chikungunya Zika Vírus.

Quanto à abordagem ou enfoque dos artigos analisados, verificamos a de três perspectivas temáticas: auto-regulamentação e/ou regulamentação da publicidade sob sua perspectiva legal, com 43 ou $(39,1 \%)$ dos trabalhos, as mensagens persuasivas na presença estrutura conteudista das peças publicitárias com 41 ou (37,3\%), e o mercado e/ou consumo com $26(23,6 \%)$ dos trabalhos. 
Figura 6 - Número de Artigos de Acordo com Enfoque

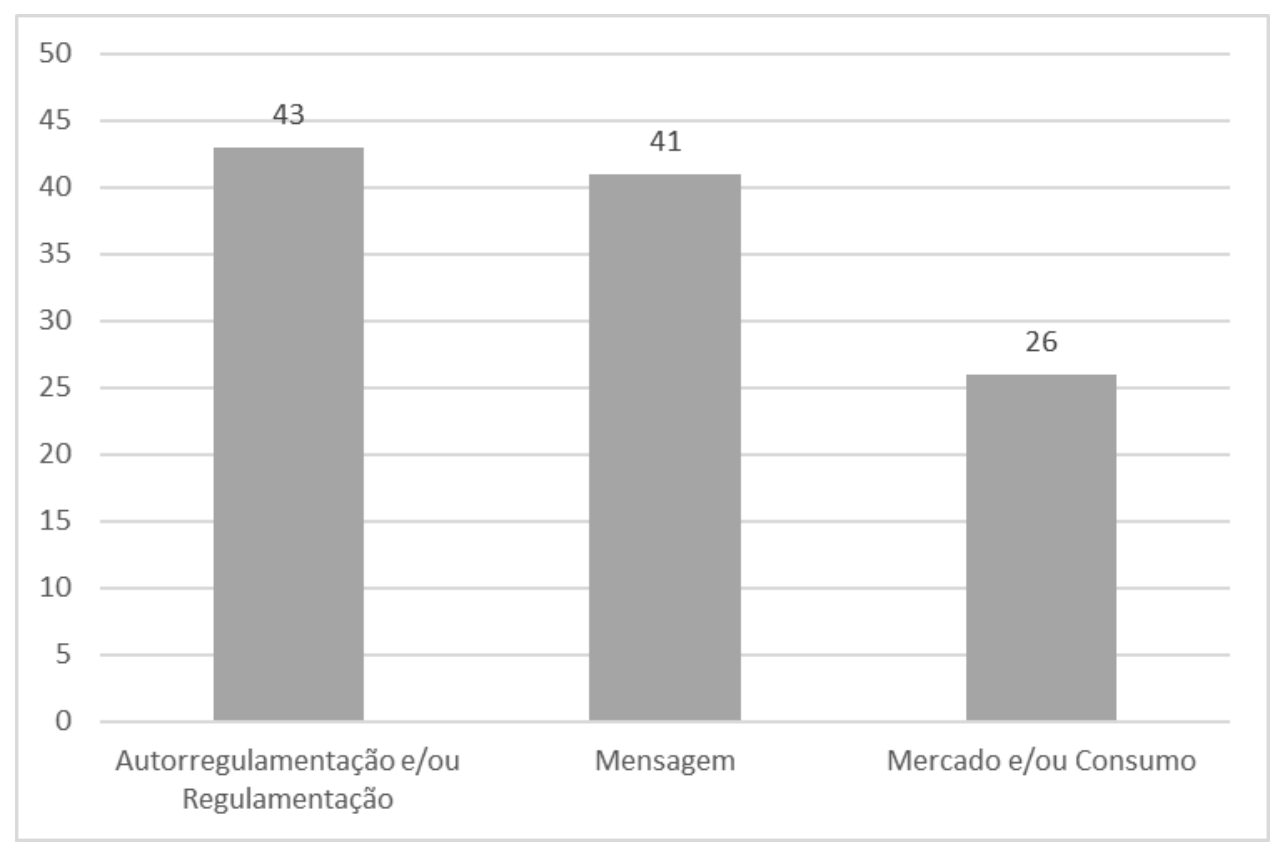

Fonte: Elaborado pelos autores.

Os estudos sobre auto-regulamentação e/ou regulamentação publicitária se fizeram a partir das legislações e acordos políticos que envolviam a publicidade propostas pelos órgãos responsáveis pelos códigos deontológicos da área. O objetivo era o de avaliar tantas normas existentes quanto acordos recém firmados sobre a regulamentação da propaganda com sua respectiva eficiência e ineficiência no impacto da saúde pública.

Nos trabalhos em que o enfoque foi a mensagem, os trabalhos propuseram-se a realizar estudos de "análise de conteúdo" das mensagens publicitárias veiculadas nos diversos meios de comunicação, objetivando tanto determinar o impacto e a frequência de determinado produto ou termo que atinge a saúde da população bem como averiguar a linguagem utilizada para mobilizar os consumidores e os impactos na saúde pública.

Por fim, os estudos que focaram no mercado e/ou consumo tiveram como objetivo analisar a estratégias mercadológicas empregadas pelas empresas dos diversos produtos temáticos da saúde e suas consequências diretas no consumo das populações, como já apontamos, dos alimentos, medicamentos e substâncias viciantes. 


\section{CONSIDERAÇÕES FINAIS}

A Coleção Saúde Pública é um importante espaço para se ter acesso ao vasto conhecimento sobre saúde pública e temáticas relacionadas. A publicidade é uma estratégia influenciadora do comportamento das pessoas, capaz de afetar a saúde, tornando-se em um importante objeto de estudo, tanto da área da saúde quanto das ciências sociais aplicadas.

Para Brofman (2018) em seu artigo “A Importância das Publicações Científicas” as revistas acadêmicas "são consideradas como o modo mais rápido e economicamente viável para os pesquisadores fazerem circular e tornar visíveis os resultados do seu trabalho", e as revistas indexadas pela Coleção Saúde Pública da SciELO possibilitam que esse conhecimento seja disseminado de forma gratuito e credível, sendo fonte de conhecimento das preocupações de estudiosos e pesquisadores que se debruçaram sobre saúde pública e publicidade.

O estudo demonstrou uma pequena quantidade de publicações ao longo dos últimos 35 anos. O encontro de 110 artigos publicados significa uma média de 3,14 artigos publicados por ano. Outro aspecto relevante foi a área de atuação dos pesquisadores que se debruçaram sobre o objeto de estudo aqui selecionado. A predominância dos estudos relacionados às formações das Ciências da Saúde revela a noção da importância que o papel social tem sobre o desenvolvimento da saúde e doença, mas que não tem atraído as atenções dos pesquisadores das ciências sociais aplicadas.

O vislumbre do papel do ambiente social atuando no desenvolvimento da saúde e doença na sociedade por esses pesquisadores poderia maximizar pesquisas voltadas às estratégias de gerenciamento e autogerenciamento da saúde da população, proporcionando sugestões de soluções requeridas para tantos problemas atuais, como já fazem, mesmo que com pouca dedicação, os pesquisadores da área da saúde.

Ademais, os temas trabalhados em estudo têm recaído invariavelmente sobre questões da regulamentação publicitária, das mensagens persuasivas (análises do seu potencial persuasivo) e mercado de consumo, sobretudo, de produtos e substâncias que ocasionam mal à saúde ou que promoveriam a saúde, como no caso de medicamentos, vacinas e uso de preservativos.

Por fim, vimos que a maioria dos estudos estavam concentrados em periódicos brasileiros e foram realizados por pesquisadores brasileiros. Desse modo, observamos a relevância de aprofundar, de forma qualitativa, a literatura publicada sobre publicidade e 
saúde pública para demonstrar os impactos da atividade no meio social e sua real capacidade de mobilização dos comportamentos em prol à saúde coletiva.

\section{REFERÊNCIAS}

ABRASCO. Forum de Editores saude Pública. Disponível em: https://www.abrasco.org.br/site/forumdeeditoresdesaudecoletiva/colecao-scielo-saude-publica-definecomite-consultivo/58. Acesso em 01 de abril de 2019.

. Formação e Educação nova Interface da Scielo. Disponível:

https://www.abrasco.org.br/site/outras-noticias/formacao-e-educacao/nova-interface-scielo/34077/. Acesso $01 \mathrm{~d}$ abril de 2019.

BAUMAN, Z. Vida para Consumo: a transformação das pessoas em mercadoria. Rio de Janeiro: Zahar, 2008.

BROFMAN, Paulo Roberto. A importância das publicações científicas. Revista Telfract, v. 1, n. 1, 2018.

COELHO, Cláudio Novaes Pinto. Publicidade: É possível escapar? São Paulo: Paulus, 2003.

CARRASCOZA, João Anzanello. Razão e sensibilidade no texto publicitário: como são feitos os anúncios que contam histórias. Futura, 2004.

CARVALHO, de Nelly. Publicidade: a linguagem da sedução. Universidade Federal de Pernambuco: Ática, 2004.

, Nelly de. Linguagem da publicidade. Recife: Editora UFPE, 2014.

CORCORAN, Nova (Ed.). Communicating health: strategies for health promotion. Sage, 2013.

GIL, Antonio Carlos. Métodos e técnicas de pesquisa social. 3. ed. São Paulo: Atlas, 1991.

FEDERIGUI, Suzana Maria Pimenta Catta Preta. Publicidade abusiva:incitação à violência. São Paulo: Juarez de Oliveira, 1999.

KOTLER, Philip; KELLER, Kevin Lane. Administração de Marketing. Tradução de Sônia Midori Yamamoto. Revisão técnica Edson Crescitelli, v. 14, 2012.

LAKATOS, E. M; MARCONI, M. de A. Metodologia do Trabalho Científico. 6. ed. São Paulo, 2001.

MATTAR, Fauze Najib. Pesquisa de marketing: metodologia, planejanento. 4. ed. São Paulo: Atlas, 1997.

MUNIZ, Eloá. Publicidade e propaganda origens históricas. Caderno Universitário, v. 148, 2004.

PINTO, Alexandra Guedes. Publicidade: um discurso de sedução. Porto Editora, 1997.

ROJAS RAJS, Soledad. La representación de servicios de salud en la televisión mexicana: potenciales consecuencias en las subjetividades en salud. Salud colectiva, v. 12, p. 189-201, 2016. 
SCIELO, 20 ANOS. Rede SciELO Saúde Pública. Disponível em:

https://www.scielo20.org/redescielo/wp-content/uploads/sites/2/2018/09/Informe-SciELO-

Sa\%C3\%BAde-P\%C3\%BAblica.pdf. Acsso em 01 de abril de 2019.

SCHIAVO, Renata. Health communication: From theory to practice. John Wiley \& Sons, 2013.

SCHRODER, Kim; VESTERGAARD, TORBEN. A linguagem da propaganda. Trad. de João Alves dos Santos. São Paulo: Martins Fontes, 2004.

SILVA, Edna Lúcia da; MENEZES, Estera Muszkat. Metodologia da pesquisa e elaboração de dissertação. 2001.

YOM-TOV, Elad et al. The effectiveness of public health advertisements to promote health: A randomized-controlled trial on 794,000 participants. NPJ digital medicine, v. 1, n. 1, p. 1-6, 2018.

Original recebido em: 16 de março de 2020

Aceito para publicação em: 28 de setembro de 2021

\section{Dhione Oliveira Santana}

Mestre em Comunicação pela Universidade Federal de Sergipe e graduado em Comunicação Social - Bacharelado em Publicidade e Propaganda. Tem interesse nos estudos relacionados com Marketing e Comunicação, mas especificamente sobre Comunicação Publicitária,

Relações Públicas, Comunicação e Saúde, Ética e Comportamento do Consumidor.

\section{Raquel Marques Carriço Ferreira}

Professora Associada da Universidade Federal de Sergipe UFS, atuando na graduação e no programa de pós-graduação em Comunicação Social. Publicitária, mestre pela Universidade Metodista de São Paulo (2003), doutora pela Universidade Nova de Lisboa com sanduíche na Universidade de Leeds, Inglaterra (2011), e pós-doutora pelo ISCTE - Instituto Universitário de Lisboa (2017). Tem experiência na área de Sociologia Aplicada, trabalhando com os temas das Teorias da Comunicação, Pesquisa Aplicada, Estudos da Audiência e Recepção, Comunicação e Saúde, Ética e Legislação Publicitária, Planejamento e Comunicação Integrada. Seu campo de estudo está circunscrito na dinâmica de interação do indivíduo com os meios de comunicação ou outro contexto social mediado por plataformas comunicacionais, conformando o nexo da produção das mensagens e seu consumo. Dentre diversos artigos e capítulos de livros, publicou dois livros, Telenovelas Brasileiras e Portuguesas: Padrões de

Audiência e Consumo, editora EDISE (EDITAL FAPITEC/SE/FUNTEC/SEGRASE No 10/2014 - PROGRAMA DE AUXÍLIO AO PESQUISADOR PARA PUBLICAÇÕES

CIENTÍFICAS); e Casos do Cotidiano: o discurso da Publicidade em Revista, pela editora UFS (EDITAL 001/2019 PROGRAMA EDITORIAL DA UFS), ambos resultados de editais de financiamento com conselho editorial. Foi pesquisadora do CIMJ - Centro de Investigação

Media e Jornalismo da Faculdade de Ciências Sociais e Humanas (FCSH) da Universidade 
NOVA de Lisboa, é pesquisadora do CIES-IUL - Centro de Investigação e Estudos de Sociologia do Instituto Universitário de Lisboa (ISCTE-IUL) e coordena o RECEPCOM -

Grupo de estudos da Produção e Recepção Midiática UFS/CNPq.

\section{(-) $\odot \Theta(0$}

Esta obra está licenciada com uma Licença

Creative Commons Atribuição-NãoComercial-CompartilhaIgual 4.0 Internacional 